\title{
Planar Asymmetrical U-Slot Patch Antenna for C and X Band Applications
}

\author{
Neha Pathak \\ Lakshmi Narain College of \\ Technology Excellence Bhopal, India
}

\author{
Rajdeep Shrivastava \\ Lakshmi Narain College of \\ Technology Excellence Bhopal, India
}

\begin{abstract}
The compact multi band antennas are the demand of the new evolving technology. A triple band antenna for which two bands, are in C-band having bandwidths $134 \mathrm{MHz}$ and $87.5 \mathrm{MHz}$. The center frequency for first band of bandwidth $134 \mathrm{MHz}$ is $5.37 \mathrm{GHz}$ and for second band of bandwidth $87.5 \mathrm{MHz}$ is $5.88 \mathrm{GHz}$. The third band lies in the frequency range of X-band having bandwidth $673 \mathrm{MHz}$ with center frequency $11.36 \mathrm{GHz}$. By cutting five asymmetrical U-slots, we can make U-shaped patch antenna. Advantages of this structure are: Simple feed, single layer structure, Simple structure antenna, freedom of one extra degree can be achieved by the asymmetry of U-slot arm. The simulation results are compared with the previous results. The performance of our proposed antenna is better.
\end{abstract}

\section{Keywords}

U-slot antenna, micro-strip patch antenna, frequency selective surfaces, three bands, substrate integrated waveguide.

\section{INTRODUCTION}

There are various antenna designs in the research study. The patch antennas are most preferred and applicable antennas. Four U-slot antennas and the substrate integrated waveguide fed microstrip patch antenna discussed in the [1]. Here in this paper we are modifying the one U-slot antennas [8] and taking the different design modifications. Many years ago these concepts of multi-band communication, multifunction application and miniaturization has been proposed. Main advantages of multi-band system are that, interference in one band system, the other can still work easily. The four U-slots design in previous study having four asymmetrical $U$ slots patch fed by a coaxial probe [2]. U slot antenna is principally used for the operating frequencies at $3.35 \mathrm{GHz}, 3.70 \mathrm{GHz}$, for $\mathrm{S}$ band and for $\mathrm{C}$ band it operates at $5.20 \mathrm{GHz}$ and $5.80 \mathrm{GHz}$.

Here in [3], designed a patch antenna which is for wide band applications and was fed by L probe. By having U-slot patch many more bands can be achieved. Main advantages of this U-shaped antenna were simple layer structure. Impedance bandwidth can be improved by having this antenna. The structure of U-shaped has presented to design for circularly polarized dual band antenna which was fed by coplanar waveguide in [4]. Impedance bandwidth for this antenna was $40 \%$, which is between 1.72 to $2.58 \mathrm{GHz}$. Electrically size of an antenna was small and it was $240 \mathrm{~mm}$. Peak gain of an antenna was $2 \mathrm{dBi}$. This antenna was good for small wireless devices like Bluetooth, Wi-Fi etc [5].

When two antennas are set in the sequence, then gap in between the two antennas are adjusted to get an effective secondary resonance in [6]. Reconfigurable beam steering by using a patch antenna with cutting of U-slots for wearable cloth applications. This antenna was designed on the fabric substrate and operates at the operating frequencies at $6.0 \mathrm{GHz}$. in [7]. The U-shaped slot was having an open ended U-slot and the dimension of feeding line is $58 \mathrm{~mm} \times 12 \mathrm{~mm}$. The monopole mode and the slot mode are the two modes which were excited. Parametric discussions had discussed here [9].

In [10], microstrip patch antenna which was used in wireless communication applications and for Wi-Max/WLAN applications. The operating frequencies were $2.45-2.57 \mathrm{GHz}$ and 5.1-5.54 GHz. The substrate used was Rogers RT/duroid 5880 which has low dielectric constant of 2.2. In [11], various topologies of U-slot antenna illustrated and these include various bands like wideband, dual band and triple band operation by having various frequency ratios. It can be used as circular polarization applications too. In [12], Main aim of antenna is to get wider bandwidth and at the selected frequency. The array uses at the base of the substrate and it was fed by proximity coupling and size was $50 \times 50 \mathrm{~mm}$ in [13]. A single layer wideband U-slot patch antenna, where line fed U-slot rectangular antenna array [14]. When created two different frequency bands with different polarization, two longitudinal and transverse slots were responsible for it for increasing the gain and bandwidth [15].

The proposed antenna presents a simple single layer structure. The five U-slots patch antenna designed by cutting five asymmetrical U-slots in the patch. The rest of the paper work is organized as follows: the 2nd section presents the proposed design. The 3 rd section covers the simulated results. Next $4^{\text {th }}$ section concludes the paper.

\section{ANTENNA DESIGN}

\subsection{Antenna Design}

The geometry of the proposed Planar Asymmetrical U-Slot Patch Antenna for C and X Band Applications is shown in Fig. 1. By cutting five asymmetrical U-slots in a single layer patch, the triple band higher gain bandwidth performances can be achieved. The dimensions of patch with length $\mathrm{L}=25 \mathrm{~mm}$ along $\mathrm{y}$-axis, the width $\mathrm{W}=25 \mathrm{~mm}$ along $\mathrm{x}$-axis, and height $\mathrm{h}$ $=1.6 \mathrm{~mm}$ along $\mathrm{z}$-axis. A square copper plate is used as the ground plane under the patch. The coaxial probe is connected to the patch for feeding connectivity and the substrate air was used. The proposed designed antenna is simulated on computer simulation technology (CST) microwave studio antenna software. The final optimized parameters of the antenna are listed in Table 1.

\subsection{Working Mechanism and Design Guidelines}

Strategy was to firstly design a U-slot patch antenna and then secondly introduce the second U-slot to produce a notch at the central frequency, so that two sub-bands can be achieved by dividing the total bands. After the third and the fourth U-slots were introduced for making the two notches at the central frequencies of the two sub-bands so that the sub-bands can be divided into four bands whenever required. The fifth $U$ slot 
provides a shift in the $\mathrm{C}$ bands to a lower frequency side. The central frequencies of the three bands required are $f_{1}=5.37$ $\mathrm{GHz}, f_{2}=5.88 \mathrm{GHz}, f_{3}=11.36 \mathrm{GHz}$. The notch frequencies were expected to be located at the centers between two adjacent frequencies. They were $5.625 \mathrm{GHz}, 8.62 \mathrm{GHz}$.

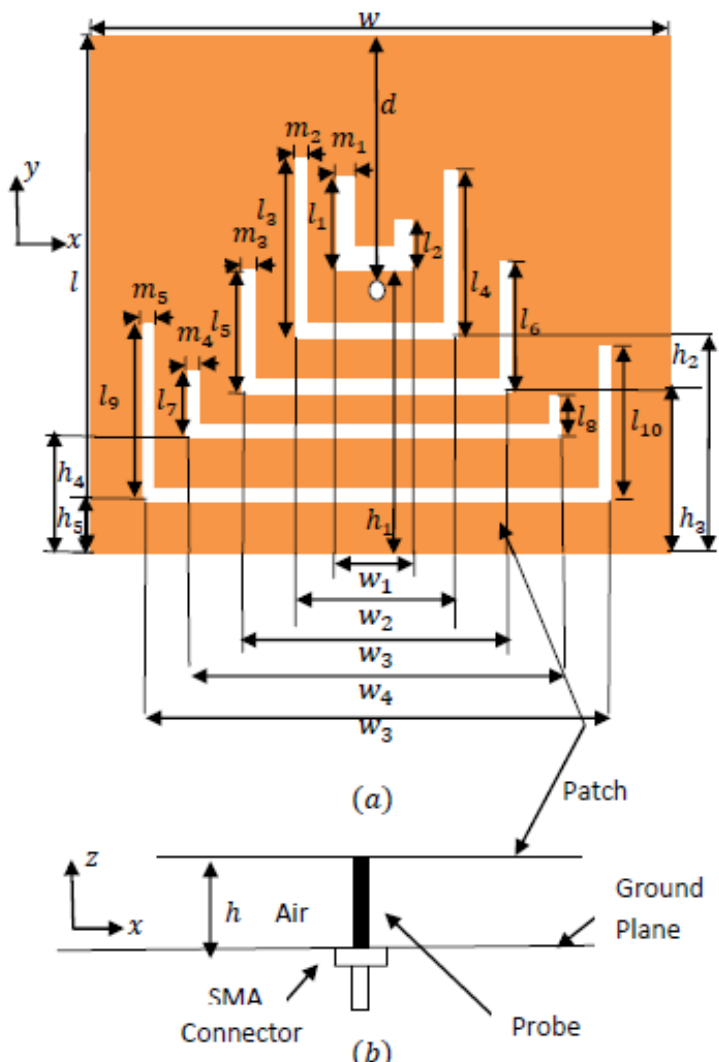

(b)

Fig 1: Geometry of the three-band patch antenna, (a) Patch with five U-slots, (b) Cross-sectional view

The guidelines for designing an antenna are below. The five U-slot patch antennas were designed firstly by having parameters $w, l, h, l_{1}, l_{2}, m_{1}$ and $w_{1}$ using the following formulas [4]

$$
\begin{aligned}
& \omega=\frac{c}{2 f_{r}} \sqrt{\frac{2}{\varepsilon_{r}+1}} \\
& l=\frac{c}{2 f_{r} \sqrt{\varepsilon_{r}}}-2 \Delta l
\end{aligned}
$$

Table 1. Optimized dimensions of the antenna (unit: $\mathbf{m m}$ )

\begin{tabular}{|c|c|c|c|}
\hline Parameter & Value & Parameter & Value \\
\hline $\boldsymbol{l}_{\mathbf{1}}$ & 7 & $w_{2}$ & 7.2 \\
\hline $\boldsymbol{l}_{\mathbf{2}}$ & 5 & $w_{3}$ & 9 \\
\hline $\boldsymbol{l}_{\mathbf{3}}$ & 8 & $w_{4}$ & 11.25 \\
\hline $\boldsymbol{l}_{\mathbf{4}}$ & 7.5 & $w_{5}$ & 13 \\
\hline $\boldsymbol{l}_{\mathbf{5}}$ & 4.75 & $h_{1}$ & 3.9 \\
\hline $\boldsymbol{l}_{\mathbf{6}}$ & 5 & $h_{2}$ & 3.5 \\
\hline $\boldsymbol{l}_{\mathbf{7}}$ & 2.25 & $h_{3}$ & 2.5 \\
\hline
\end{tabular}

\begin{tabular}{|c|c|c|c|}
\hline $\boldsymbol{l}_{\mathbf{8}}$ & 1 & $h_{4}$ & 1.5 \\
\hline $\boldsymbol{l}_{\mathbf{9}}$ & 5.4 & $h_{5}$ & 0.5 \\
\hline $\boldsymbol{l}_{\mathbf{1 0}}$ & 5 & $w$ & 25 \\
\hline $\boldsymbol{m}_{\mathbf{1}}$ & 0.9 & $l$ & 25 \\
\hline $\boldsymbol{m}_{\mathbf{2}}$ & 0.8 & $d$ & 12.5 \\
\hline $\boldsymbol{m}_{\mathbf{3}}$ & 0.5 & $h$ & 2.5 \\
\hline $\boldsymbol{m}_{\mathbf{4}}$ & 0.5 & $t$ & 37.83 \\
\hline $\boldsymbol{m}_{\mathbf{5}}$ & 0.5 & $G_{L}$ & 2 \\
\hline $\boldsymbol{w}_{\mathbf{1}}$ & 6.5 & & \\
\hline & $\varepsilon_{e f f}=\frac{\varepsilon_{r+1}}{2}+\frac{\varepsilon_{r-1}}{2}\left(1+12 \frac{h}{w}\right)^{\frac{-1}{2}}$ \\
\hline
\end{tabular}

$\Delta l=0.412 h \frac{\left(\epsilon_{\text {eff }+0.3}\right)\left(\frac{w}{h}+0.264\right)}{\left(\epsilon_{e f f-0.258)}\right)\left(\frac{w}{h}+0.8\right)}$

$\omega_{1}=\frac{c}{\sqrt{\varepsilon_{r e f f}} \mathrm{f}_{2}}-2\left(l+2 \Delta l-m_{1}\right)$

$\frac{l_{1}}{\omega} \geq 0.3, \frac{l_{2}}{\omega} \geq 0.3$ and $\frac{l_{1}}{\omega_{1}} \geq 0.75, \frac{l_{2}}{\omega_{1}} \geq 0.75$

$h \geq 0.06 \frac{\lambda_{r}(\text { air })}{\sqrt{\varepsilon_{r}}}$

The various parameter comparisons are shown in Table 3 . Main objective of the central frequency is to get s-parameter below $-10 \mathrm{~dB}$ for optimal operation. Main aim of the $\mathrm{S}$ parameter is that many bands should achieve for capturing the signals at longer distances. For having distant signals, we require more bands. The final total length is listed in Table 2 .

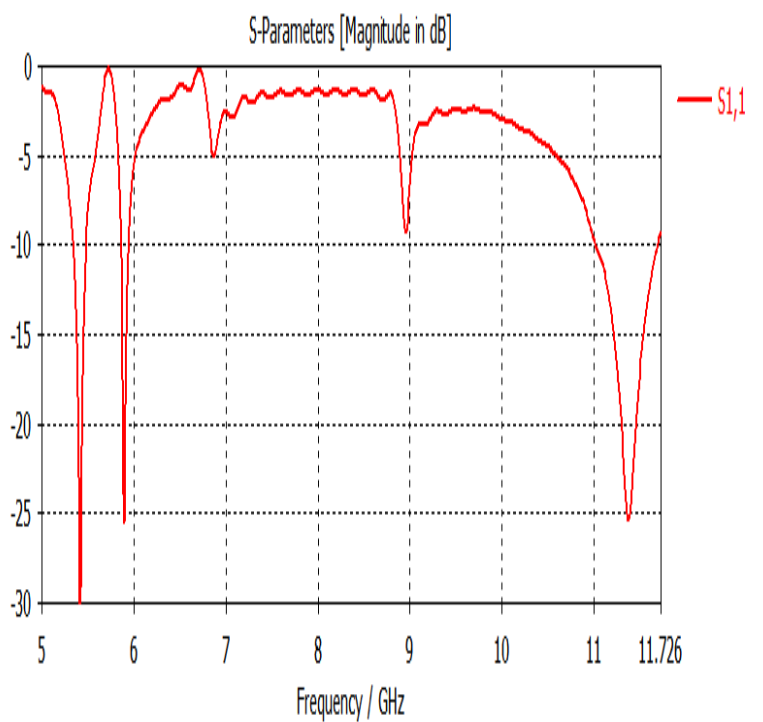

Fig 2: S Parameters for five U-slots patch antenna 


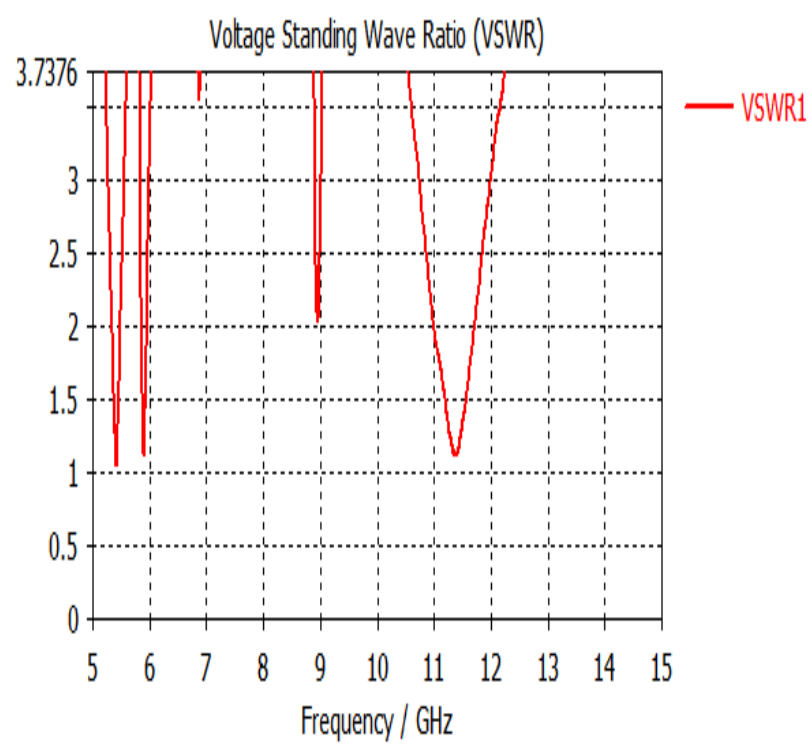

Fig 3: VSWR for five U-slot patch antenna

The five-U-slot antenna design is suitable for generating the central frequency $5.37 \mathrm{GHz}, 5.88 \mathrm{GHz}, 11.36 \mathrm{GHz}$. The SParameters for U-slot patch antenna is shown in Fig 2 and the VSWR for the five U-slot patch antennas is shown in Fig 3. The results of an antenna with triple band are listed in Table 3. The $\mathrm{S}$ parameter means output comes below-10 dB and the VSWR should come below 2. In triple bands, here in this antenna covers $\mathrm{C}$ and $\mathrm{X}$ band and having various applications which is cover in conclusion section.

Table 2. The relationship between frequency of band notch and total $u$-slot length (the subscripts of the free space wavelengths are the corresponding frequencies)

\begin{tabular}{|c|c|c|}
\hline Antenna & $\begin{array}{c}\text { Frequency of } \\
\text { Band Notch }\end{array}$ & Total U-slot length \\
\hline Five-U-slot & $5.625 \mathrm{GHz}$, & $L_{U 5 t}=16.7 \mathrm{~mm}$, \\
Antenna & $8.62 \mathrm{GHz}$ & $L_{U 5 t}=21.1 \mathrm{~mm}$, \\
& & $L_{U 5 t}=17.75 \mathrm{~mm}$, \\
& & $L_{U 5 t}=13.5 \mathrm{~mm}$, \\
& & $L_{U 5 t}=22.4 \mathrm{~mm}$ \\
\hline
\end{tabular}

Table 3. The Results of antenna with Triple Band

\begin{tabular}{|c|c|c|c|}
\hline Parameter & \multicolumn{3}{|c|}{ Results } \\
\hline $\begin{array}{c}\text { Centre } \\
\text { Frequency }\end{array}$ & $5.37 \mathrm{GHz}$ & $5.88 \mathrm{GHz}$ & $\begin{array}{c}11.36 \\
\mathrm{GHz}\end{array}$ \\
\hline S11 & $-30 \mathrm{~dB}$ & $-25.47 \mathrm{~dB}$ & $25.258 \mathrm{~dB}$ \\
\hline VSWR & 1.0499 & 1.1506 & 1.114 \\
\hline Gain & $7.174 \mathrm{~dB}$ & $6.308 \mathrm{~dB}$ & $6.188 \mathrm{~dB}$ \\
\hline B.W. & $2.58 \%$ & $1.46 \%$ & $5.92 \%$ \\
\hline
\end{tabular}

\section{SIMULATED RESULTS}

The five U-slot patch antenna design and it simulated results are compared with single U-slot patch antenna. The parameters are computed by using CST software. Investigating the relationship between center frequencies of U-slot lengths, different parameters as S-parameter, VSWR, far-field studies are carried out.

The measured impedance bandwidths with - $10 \mathrm{~dB}$ reflection coefficients of the five U-slot patch antennas were $2.58 \%$, $1.46 \%, 5.92 \%$. The simulated result shows the center frequencies corresponding to WLAN, Uplink and Downlink for satellite communication were $5.37 \mathrm{GHz}, 5.88 \mathrm{GHz}$, and 11.36 GHz. Notch frequencies did not affected by the additional fifth U-slot and it gives the best impedance matching.

The gain obtained by proposed antenna from Table 4 is $7.174 \mathrm{~dB}$ as compared to the previous antenna design [8]. Here in this antenna comparison occurs between the single U-slot and the five U-slot patch antennas which give better results in bands as compared to compared single U-slot antenna

Table 4: Comparison of proposed patch antenna and antenna taken for comparison [8]

\begin{tabular}{|c|c|c|c|c|c|}
\hline \multirow{2}{*}{ Parameter } & \multicolumn{3}{|c|}{ Proposed Patch Antenna } & \multicolumn{2}{c|}{$\begin{array}{c}\text { Antenna Taken for } \\
\text { Comparison [8] }\end{array}$} \\
\hline $\begin{array}{c}\text { Centre } \\
\text { Frequency }\end{array}$ & $5.37 \mathrm{GHz}$ & $5.88 \mathrm{GHz}$ & $11.36 \mathrm{GHz}$ & $3.5 \mathrm{GHz}$ & $5.8 \mathrm{GHz}$ \\
\hline Bands & \multicolumn{3}{|c|}{ Triple } & \multicolumn{2}{c|}{ Double } \\
\hline Gain & $7.174 \mathrm{~dB}$ & $6.308 \mathrm{~dB}$ & $6.188 \mathrm{Db}$ & $6.2 \mathrm{dBi}$ & $6.5 \mathrm{dBi}$ \\
\hline B.W. & $2.58 \%$ & $1.46 \%$ & $5.92 \%$ & $1.0 \%$ & $3.1 \%$ \\
\hline
\end{tabular}


The resulting four-band antenna had frequency ratios $f_{2} / f_{1}=$ 1.09 , and $f_{3} / f_{1}=2.11$ where $f_{3}, f_{2}$ and $f_{1}$ were the center frequencies of the upper, middle and lower frequency bands. The fabrication and assembly errors of the longest U-slot $\left(l_{9}+\right.$ $l_{10}+w_{5}-2 m_{5}$ ) and the probe position $d$ creates the difference between the theoretical and simulated $S_{11}$, which results of the first, second and third frequency bands.

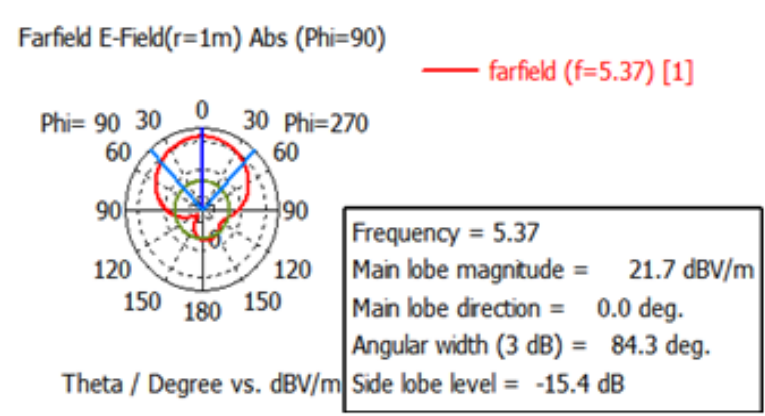

(a)

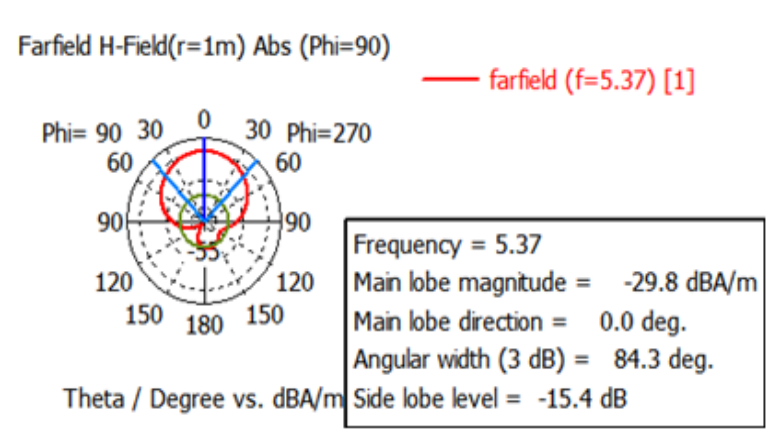

Fig 4: Measured and simulated normalized radiation patterns of the antenna at $5.37 \mathrm{GHz}$

The radiation patterns can be simulated in the E-plane and $\mathrm{H}$ plane at $5.37 \mathrm{GHz}, 5.88 \mathrm{GHz}$, and $11.36 \mathrm{GHz}$ are shown in Fig. 4 to Fig. 6. It can be noted that all the cross-polarization levels are below $-10 \mathrm{~dB}$ in both E-plane and H-plane. All the gains of the notch bands are below $0 \mathrm{dBi}$. Simulation of the ground plane size variation is done for investigating the effect of the ground size on antenna gain. As the dimensions of the ground increases, the antenna gains increases in the three bands. But when the dimension of the ground increases up to $25 \mathrm{~mm}$, these gains show no significant change .This size was chosen for our design. Fig. 7 shows the photograph of the antenna.

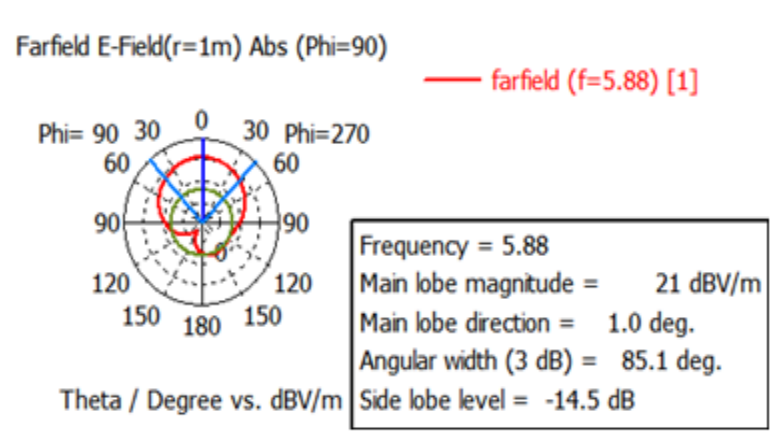

(c)

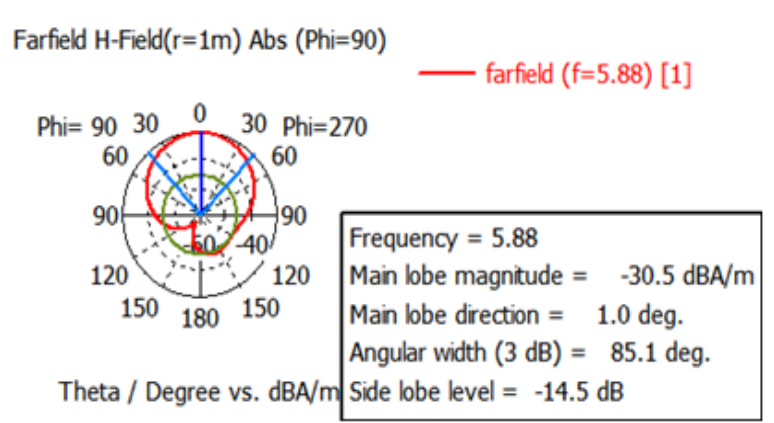

(d)

Fig 5: Measured and simulated normalized radiation patterns of the antenna at $5.88 \mathrm{GHz}$.

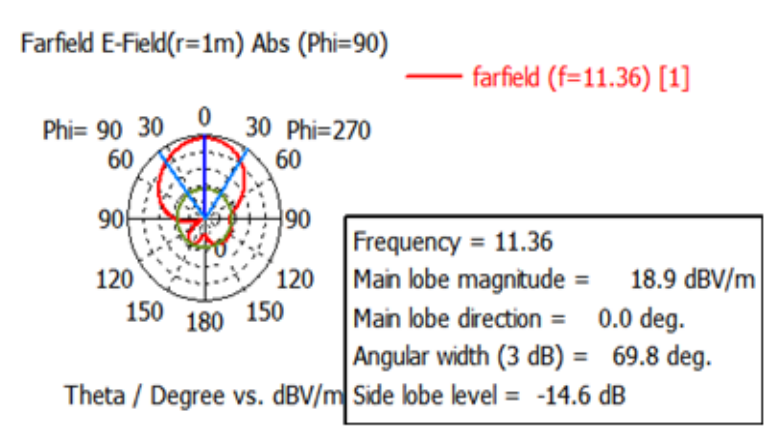

(e)

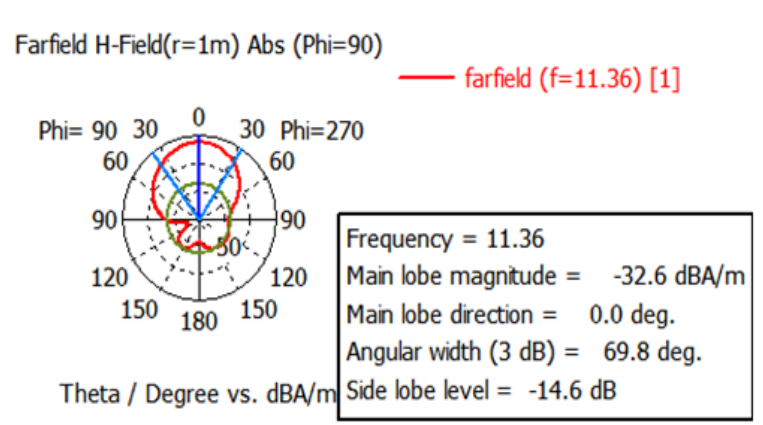

(f)

Fig 6: Measured and simulated normalized radiation patterns of the antenna at $11.36 \mathrm{GHz}$ 


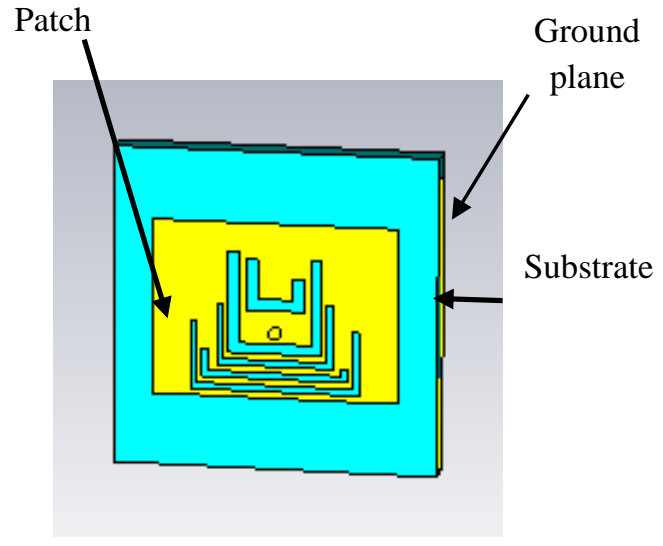

Fig 7: Photograph of the proposed antenna

\section{CONCLUSION}

The five U-slot patch antennas provide higher bandwidth applications. It presents the simple geometry of a Planar Asymmetrical U-Slot Patch Antenna for $\mathrm{C}$ and $\mathrm{X}$ Band Applications. Five asymmetrical U-slots are in this antenna and are fed by a coaxial probe. The antenna designed is capable to operate at $5.37 \mathrm{GHz}, 5.88 \mathrm{GHz}$, and $11.36 \mathrm{GHz}$. The applications of centre frequency $5.37 \mathrm{GHz}$ are for T.V. networks or raw satellite feeds at $\mathrm{C}$ band. The centre frequency $5.88 \mathrm{GHz}$ are used in areas that are subject to tropical rainfall. The centre frequency $11.36 \mathrm{GHz}$ are used by military government institutions for weather monitoring, air traffic control, maritime vessel traffic control, defence tracking and vehicle speed detection as well as used in radar applications including continuous wave, pulsed, single polarization, dual polarization at $\mathrm{X}$ band. The antenna provides impedance bandwidths with $-10 \mathrm{~dB}$ reflection coefficients of the three bands were of $2.58 \%, 1.46 \%, 5.92 \%$. The gain can also be increased for high gain applications.

\section{REFERENCES}

[1] N. Pathak, and A. Bhargava, "A comparative Analysis of Asymmetrical U-Slot and Substrate Integrated Waveguide Fed Microstrip Patch Antennna", International Journal of Computer Applications (IJCA), ISSN: 0975-8887, vol. 138, no. 11, pp. 33-36, March. 2016.

[2] S. Liu, S. S. Q. W. Wu, and D. G. Fang, "Single-Layer Single-Patch Four-Band Asymmetrical U-Slot Patch Antenna", IEEE Trans. on Antennas and Propagation, vol. 62, no. 9, pp. 4895-4899,Sep 2014.

[3] K. F. Lee, S. L. S. Yang, and A. A. Kishk, "Dual-and multiband U-slot patch antennas," IEEE Antennas Wireless Propag. Lett. vol. 7, pp. 645-647, Dec. 2008
[4] W. M. Li, B. Liu, and H. W. Zhao, "The U-shaped structure in dual-band circularly polarized slot antenna design", IEEE Antennas Wireless Propag. Lett. vol. 13, pp. 447-450, 2010.

[5] S. Wang, H. W. Lai, K. K. So, K. B. Ng, Q. Xue, and G. Liao, "Wide-band shortened patch antenna with a modified half U-slot", IEEE Antennas Wireless Propag. Lett. , vol. 11, pp. 689-692, Nov. 2012.

[6] M. N. Mahmoud and R. Baktur, "A dual-band microstrip-fed slot antenna," IEEE Trans. Antennas Propag. , vol. 59, no. 5, pp. 1720-1724, Mar. 2011.

[7] S. J. Ha and C. W. Jung, "Reconfigurable beam steering using a microstrip patch antenna with a U-slot for wearable fabric applications," IEEE Antennas and Wireless Propag. Lett. , vol. 10, pp. 1228-1231, 2011

[8] P. Nayeri, K. F. Lee, A. Z. Elsherbeni, and F. Yang, "Dual-band circularly polarized antennas using stacked patches with asymmetric U-slots", IEEE Antennas Wireless Propag. Lett., vol. 10, pp. 492-495, Oct. 2011.

[9] C. K. Hsu and S. J. Chung, "Compact antenna with Ushaped open-end slot structure for multi-band handset application”, IEEE Trans. Antennas Propag. , vol. 62, no. 2, pp. 929-932, Feb. 2014.

[10] S. Panusa and M. Kumar, "Modified U-slot microstrip patch antenna with gain enhancement", IEEE Sixth International Conference on Computational Intelligence and Communication Networks, pp. 83-86, 2014.

[11] K. F. Lee, S. L. S. Yang, and A. A. Kishk, "The versatile U-slot patch antenna", IEEE Antennas and Propag. Magazine, vol. 52, no. 1, Feb 2010.

[12] D. Meena, and R.S. Meena, "Triple band U-slot microstrip patch antenna for WLAN and wireless sensor applications", IEEE International Conference on Communication, Control and Intelligent Systems, pp. 1214, 2015.

[13] Y. Kurmi, V. Chaurasia and H. Kaptan, "Microstrip Planer Antenna Array by Proximity fed for complete $S$ Band applications", IEEE U.P. Sec. Conference on Electrical Computer and Electronics, 2015.

[14] H. Wang, X. B. Huang, D. G. Fang, "A Single Layer Wideband U-Slot Microstrip Patch Antenna", IEEE Antennas and Wireless Propag. Lett., vol. 7, pp. 9-12, 2008.

[15] L. Sabri, N. Amiri, and K. Forooraghi, "Dual band and dual polarized SIW Fed microstrip patch antenna", IEEE Antennas and Wireless Propag. Lett. , vol. 13, pp. 1605$1608,2014$. 